\title{
Profile of uncommon primary adult hepatic malignancies at a tertiary care centre
}

\author{
Eliz Thomas ${ }^{1}$, A Venkatasubramanian ${ }^{1}$ \\ ${ }^{I}$ Department of Pathology, PSG Institute of Medical Sciences \& Research, Coimbatore, India
}

\section{Keywords: \\ Hepatopathology; \\ Liver cancer; \\ Non-hepatocellular \\ liver malignancy;}

\begin{abstract}
Background: Hepatocellular carcinoma has been the most common primary malignancy of the liver in adults, followed by cholangiocarcinoma. The less common malignancies are those arising from the vascular endothelial cells, neuroendocrine cells, hematolymphoid tissues, and mesenchymal tissues. Imaging studies alone may pose a diagnostic challenge, due to the variable appearances. Histological review of the tissue specimen along with immunohistochemical stains are imperative for diagnosis. However, a multidisciplinary approach is necessary to make an accurate diagnosis and help in management.
\end{abstract}

Materials and Methods: The unusual adult primary hepatic malignancies were studied in 2 years period with clinic-radiological and biochemical correlation and also the age and sex distribution were determined. Ethical approval was obtained. Statistical analysis used: SPSS version 23.0.

Results: A total of 24 liver malignancies were encountered. Metastatic tumors and tumor-like lesions were excluded. The patient's clinico-radiological findings and laboratory investigations were noted. A total of 6 unusual non-hepatocellular malignancies were seen and identified based on morphology and special stains. Out of 6 non-hepatocellular malignancies, 3 were neuroendocrine carcinomas, 2 were leiomyosarcomas and 1 was a hematolymphoid malignancy. Radiologic impression and biochemical parameters helped arrive at a definitive opinion as the lesions were not typical of this location. A high index of suspicion along with the immunohistochemical profile finally facilitated the diagnosis.

Conclusion: The cases of primary non-hepatocellular malignancies are unexpected. A multidisciplinary approach is mandatory.

\section{Correspondence:}

\section{Dr. Eliz Thomas}

Department of Pathology

PSG Institute of Medical Sciences \& Research, Coimbatore, India

ORCID ID: 0000-0002-1247-8592

Email: elshaddai4eliz@gmail.com

Received : July $9^{\text {th }} 2020$; Accepted : September $30^{\text {th }} 2020$

Citation: Thomas E, Venkatasubramanian A. Profile of uncommon primary adult hepatic malignancies at a tertiary care centre. J Pathol Nep 2020;10: 1718-21. DOI: 10.3126/jpn.v10i2.29933

Copyright: This is an open-access article distributed under the terms of the Creative Commons Attribution 4.0 International License, which permits unrestricted use, distribution, and reproduction in any medium, provided the original author and source are credited.

\section{INTRODUCTION}

Primary liver cancers are rare. Because the liver is made up of several different types of cells, several types of tumors can originate from there. Hepatocellular carcinoma has been the most common primary malignancy of the liver in adults, followed by cholangiocarcinoma. The less common are those arising from the vascular endothelial cells, neuroendocrine cells, hematolymphoid tissues, and mesenchymal tissues. ${ }^{1}$

Many times, imaging studies alone may pose a diagnostic challenge due to the variable appearances of the tumors. Histological review of the tissue specimen, along with immunohistochemical stains is imperative for definitive 
diagnosis. A multi-disciplinary approach is necessary for accurate diagnosis and management.

\section{MATERIALS AND METHODS}

This is a retrospective study for 2 years which was conducted in a tertiary care center. The study included the collection of data from the patients' record sheets available in the Medical Records Department. Information pertaining to the cases was recorded and tabulated.

All investigated cases of primary non-hepatocellular hepatic malignancies of 2 years were included in the study. Metastatic tumors and tumor-like lesions were excluded. Approval from the Institutional Human Ethics Committee was obtained (Approval number - 19/137). All the data were analyzed using SPSS version 23.0 (Armonk, NY: IBM Corp.). It is represented as proportions and percentages.

\section{RESULTS}

We encountered a total of six unusual cases of primary nonhepatocellular hepatic malignancies which included three neuroendocrine carcinomas, two leiomyosarcomas, and one hematolymphoid malignancy. All of these cases were biopsies. The mean age at presentation for the patients was 56 years, of which the majority of them were males. No cases were reported in childhood or adolescence.

There were varied symptoms at presentation, ranging from abdominal pain to asymptomatic presentation. The most common presenting symptoms were abdominal pain and loss of appetite. Other presentations include yellowish discoloration of eyes, tiredness, and nausea. Almost all the cases had a palpable mass in the right hypochondrium. Liver enzymes were deranged in all the cases. Imaging studies done were ultrasound, computed tomography (CT) scan, or both. Diagnosis of malignancy was established for all the cases with most favoring a hepatocellular carcinoma. Of the 6 non-hepatocellular primary hepatic malignancies, three were neuroendocrine carcinomas (fig.1A-D), two were leiomyosarcomas (fig. 2A-D) and one was a hematolymphoid malignancy (fig.3A-F). Search for primary origin elsewhere was negative, and metastasis was ruled out. The diagnosis was established with the help of immunohistochemical markers.

\section{DISCUSSION}

A variety of hepatic lesions can present as hepatic masses. Amongst the malignant neoplastic lesions, primary hepatocellular carcinoma and cholangiocarcinoma are the most common. Primary non-hepatocellular hepatic malignancies although rare, are known to occur. ${ }^{2,3}$ Prior to pathological examination for primary hepatic malignancies, misdiagnosis was frequent due to similar presentation and imaging findings in both hepatocellular and nonhepatocellular malignancies. ${ }^{4,5}$

Approximately $50-90 \%$ of all neuroendocrine tumors cases are known to arise from the gastrointestinal tract and their occurrence as primary hepatic tumors is rare $(0.3 \%){ }^{6}$

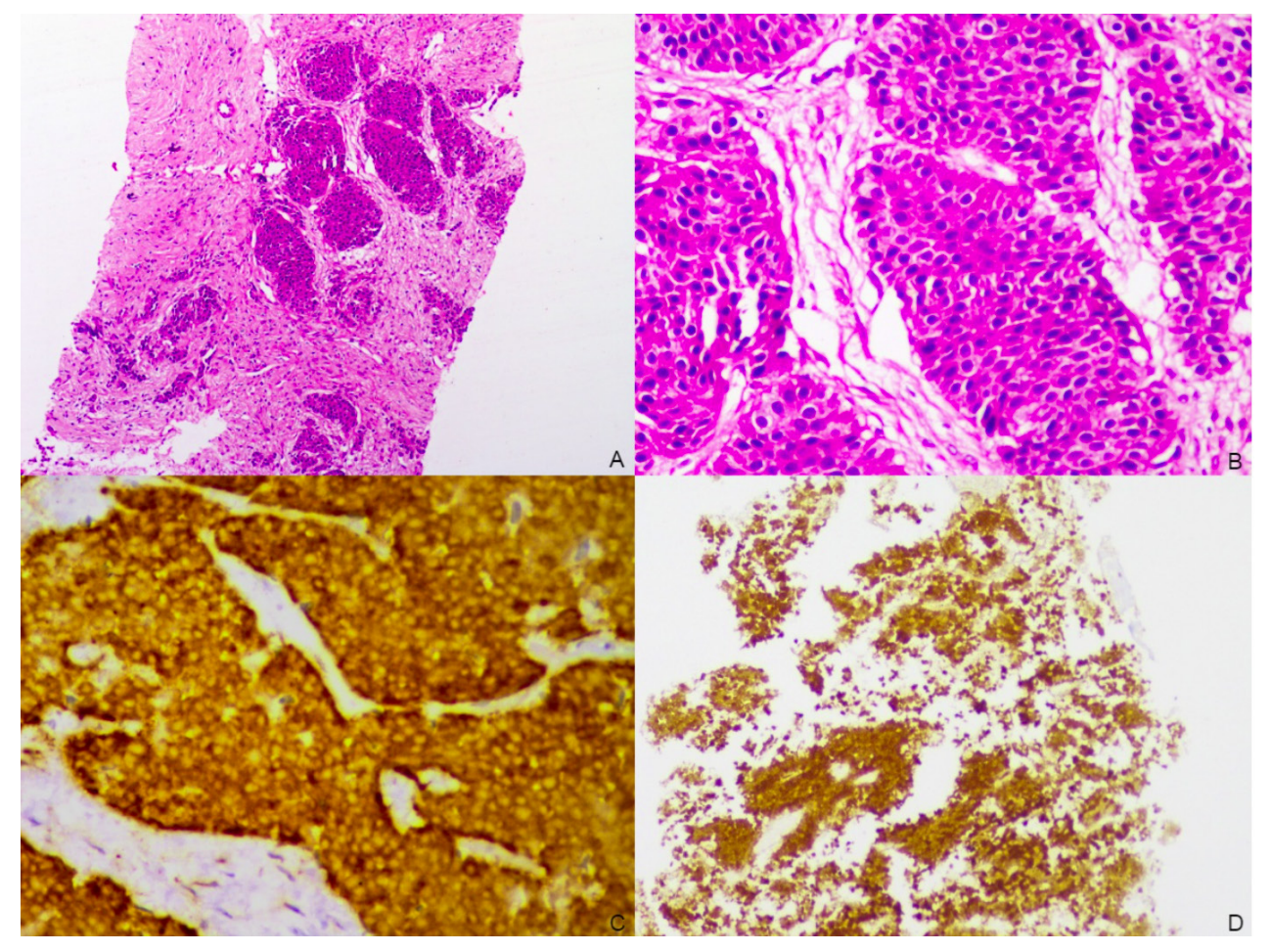

Figure 1: Neuroendocrine tumour. A) Photomicrograph showing infiltration by tumour cells arranged in nests and cords (HE stain; X100) The cells are small to medium with eosinophilic finely granular cytoplasm, round nuclei with finely stippled chromatin (HE stain; X400). The tumour cells show immunopositivity with synaptophysin (C) and chromogranin (D). 


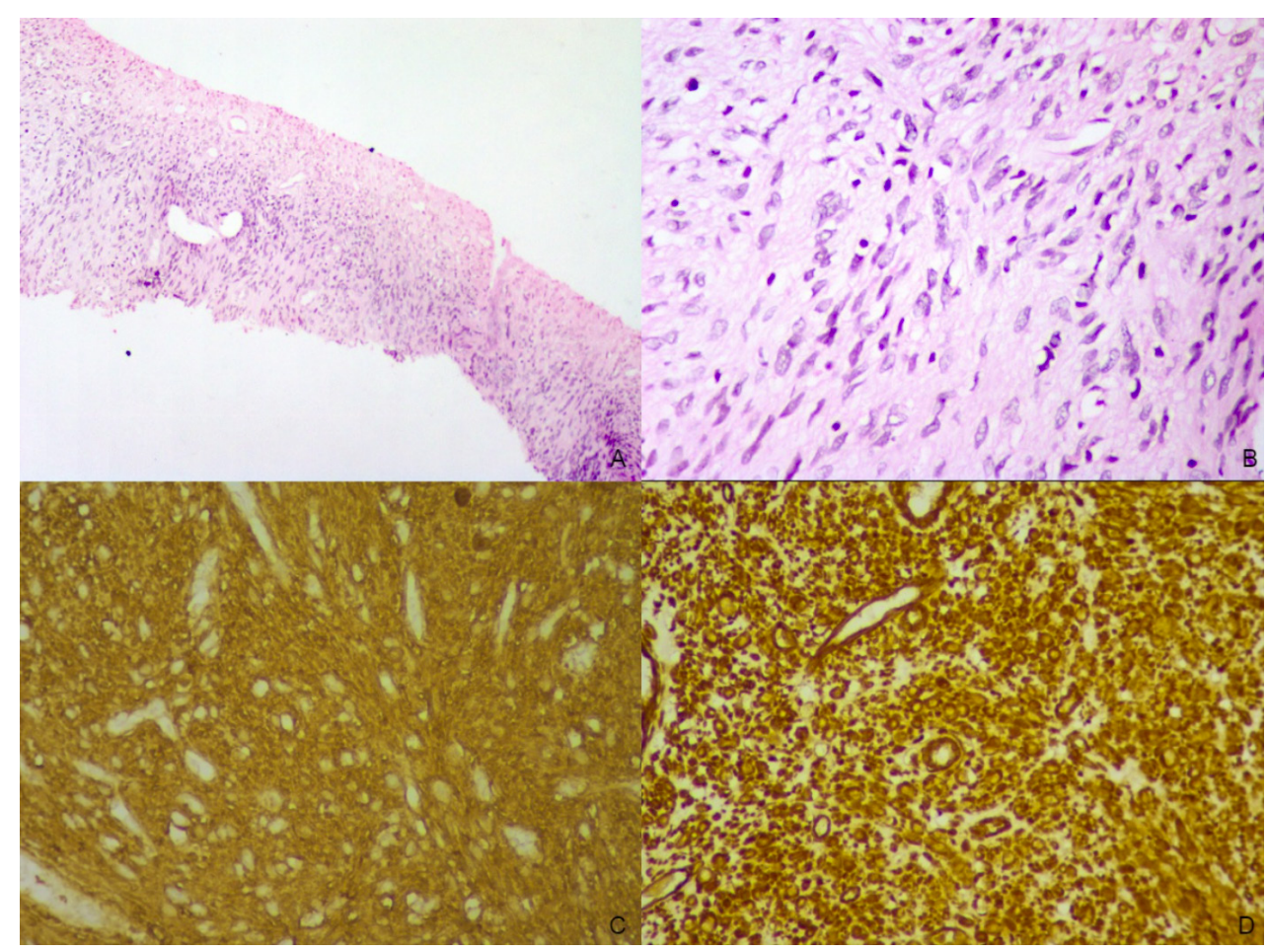

Figure 2: Leiomyosarcoma. Histopathological examination on H\&E stain showing hepatic parenchyma infiltrated by pleomorphic spindle cells arranged in palisading pattern (A: X100, B:X400). The tumour cells are positive for smooth muscle actin (C) and vimentin (D) by immunohistochemistry (100X)

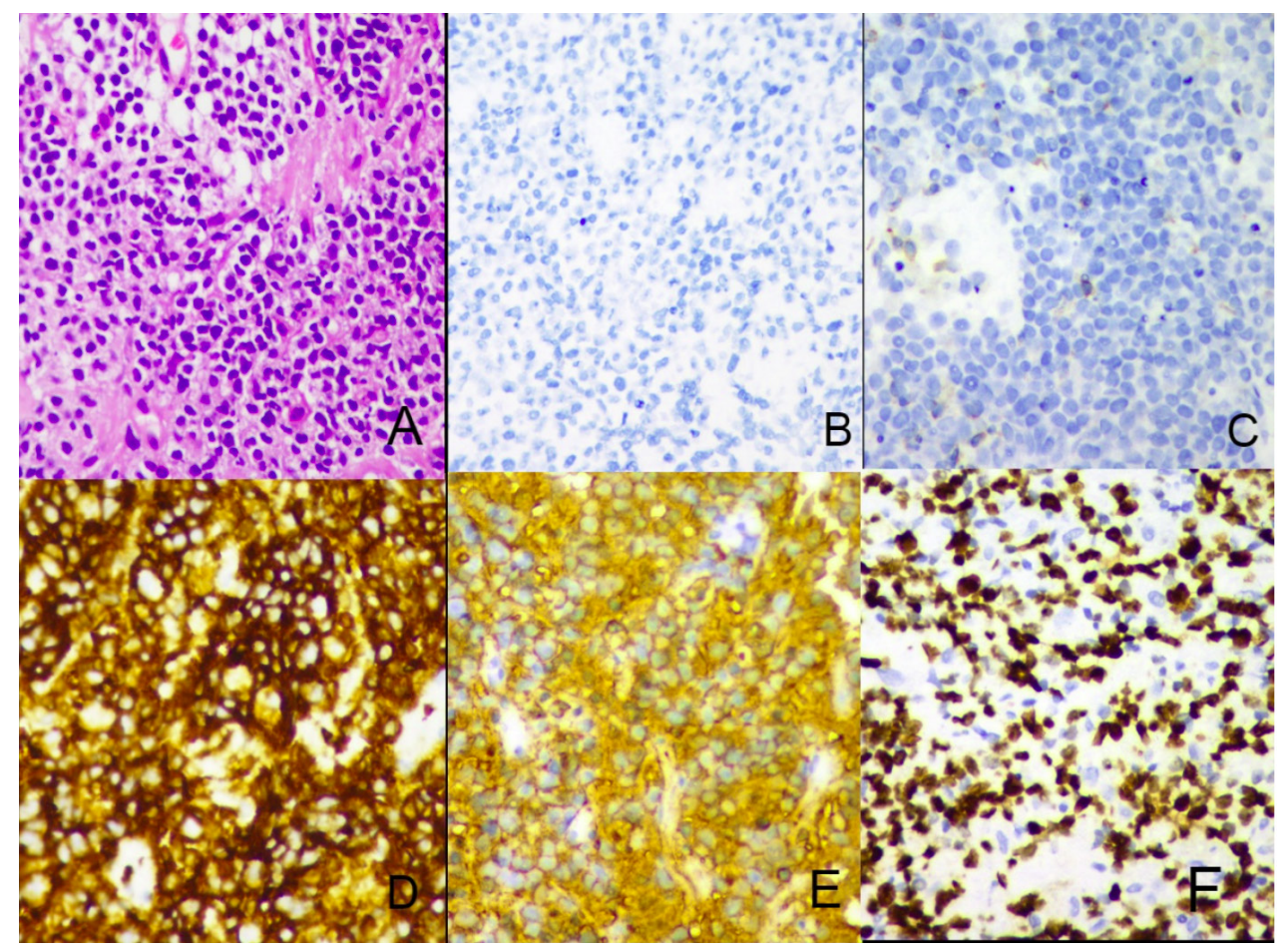

Figure 3: B-cell non-Hodgkin lymphoma. A: The tumour cells are intermediate to large and show diffuse infiltrating pattern (HE stain; X400). The tumour cells are negative for Heppar-1 (B) and CD $3(C)$. They are strongly positive for LCA (D) and CD 20 (E). The Ki-67 proliferation index $(F)$ is $>80 \%$.

A definitive diagnosis of primary neuroendocrine carcinoma is possible only after hepatic biopsy and the use of ancillary tools like special stains and immunohistochemistry. Therefore, it can be established that biopsy and pathological examination are the gold standards for diagnosis. ${ }^{2}$
On histopathological examination, neuroendocrine tumors (NET) are composed of uniform round to polygonal cells with pale eosinophilic granulated cytoplasm, monotonous, round, centrally located finely stippled nuclei, and small inconspicuous nucleoli. Mitosis and necrosis are infrequent. 
The tumor cells show immunoreactivity with synaptophysin and chromogranin and are negative for Heppar-1. This staining pattern was seen in all our cases reported as NET (fig. 1).

Mesenchymal tumors are also rarely encountered in adults. ${ }^{7}$ Amongst the primary malignant mesenchymal tumors, hepatic angiosarcomas are most common. Primary hepatic leiomyosarcoma are again rare tumors and not many cases have been reported in the literature. ${ }^{8,9}$ It is often associated with immunodeficiency or viral infections (HCV, EBV, etc). ${ }^{10}$ The cases in our study were not associated with any such underlying condition.

Histomorphology of leiomyosarcoma shows a spindle cell lesion with features of anaplasia which has to to be distinguished from other spindle cell lesions of this region.

Our cases were confirmed to be primary, by ruling out metastases from other origins. Immunohistochemical markers helped in confirming the diagnosis (fig.2)

Hematolymphoid malignancies with hepatic involvement are a relatively common presentation of the extranodal disease. Rarely, lymphomas can involve the liver exclusively (primary hepatic lymphomas). As defined by previous studies, primary hepatic lymphoma is to be considered when the patient gives a negative history of prior or subsequent lymphoma diagnosis, no biopsy-proven hematolymphoid neoplasm at a nonhepatic location, and no other reason for clinical concern for hematolymphoid malignancy elsewhere in the body. ${ }^{11,12}$ Most common primary hepatic lymphoma reported so far, is diffuse large B-cell lymphoma (DLBCL) which is closely associated with HCV infection and immunocompromised states, including HIV infection. ${ }^{13,14}$ Our case was diagnosed as primary nonHodgkin lymphoma of B-cell type and further typing could not be done as the tissue was insufficient (fig. 3). The patient was immunocompetent.

\section{CONCLUSIONS}

The correlation of clinical, serological, radiological, and histopathological findings is helpful in the early detection, diagnosis, and management of hepatic masses. Imaging studies are a reliable tool to detect hepatic malignancy. However, histological examination with immunohistochemistry remains the gold standard for diagnosis and confirmation of different types of malignancies arising from the liver.

\section{Conflict of interest: None}

\section{REFERENCES}

1. Jiang K, Al-Diffalha S, Centeno B. Primary Liver CancersPart 1. Cancer Control 2018; 25:107327481774462. Crossref

2. Chen Z, Xiao HE, Ramchandra P, et al. Imaging and pathological features of primary hepatic neuroendocrine carcinoma: an analysis of nine cases and review of the literature. Oncology Letters 2014;7:95662. $\underline{\text { Crossref }}$

3. Baek SH, Yoon JH., Kim KW. Primary hepatic neuroendocrine tumor: gadoxetic acid (Gd-EOB-DTPA)-enhanced magnetic resonance imaging. Acta Radiologica Short Reports 2013;2:6. Crossref

4. Scarsbrook AF, Ganeshan A, Statham J, et al. Anatomic and functional imaging of metastatic carcinoid tumors. Radiographics 2007;27:45576. Crossref

5. Kellock T, Tuong B, Harris AC, et al. Diagnostic Imaging of Primary Hepatic Neuroendocrine Tumors: A Case and Discussion of the Literature. Case Rep Radiol 2014;156491. Crossref

6. Camargo ÉS, Viveiros Mde M, Corrêa Neto IJ, et al. Primary hepatic carcinoid tumor: case report and literature review. Einstein 2014;12:505-8. $\underline{\text { Crossref }}$

7. Kim KA, Kim KW, Park SH, et al. Unusual Mesenchymal Liver Tumors in Adults: Radiologic-Pathologic Correlation AJR 2006;187:481-9. Crossref

8. Shivathirthan N, Kita J, Iso Y. Primary hepatic leiomyosarcoma: case report and literature review. World J Gastrointest Oncol 2011;3:14852. $\underline{\text { Crossref }}$

9. Iida $\mathrm{T}$, Maeda $\mathrm{T}$, Amari $\mathrm{Y}$, et al. Primary hepatic leiomyosarcoma in a patient with autosomal dominant polycystic kidney disease. CEN Case Rep 2017;6:74-8. Crossref

10. Zhu KL, Cai XJ. Primary hepatic leiomyosarcoma successfully treated by transcatheter arterial chemoembolization: A case report. World J Clin Cases 2019;7:525-31. Crossref

11. Yang XW, Tan WF, Yu WL, et al. Diagnosis and surgical treatment of primary hepatic lymphoma. World J Gastroenterol 2010;16:60169. $\underline{\text { Crossref }}$

12. Agmon-Levin N, Berger I, Shtalrid M, et al. Primary hepatic lymphoma: a case report and review of the literature. Age and Aging 2004;33:637-40. Crossref

13. El-Sharkawi D, Ramsay A, Cwynarski K, et al. Clinicopathologic characteristics of patients with hepatic lymphoma diagnosed using image-guided liver biopsy techniques. Leuk Lymphoma 2011;52:2130-34. Crossref

14. Noronha V, Shafi NQ, Obando JA, et al. Primary non-Hodgkin's lymphoma of the liver. Crit Rev Oncol Hematol 2005;53:199-207. $\underline{\text { Crossref }}$ 